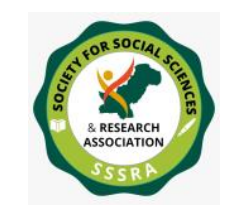

\title{
The Prospects Affecting Faculty Retention in Higher Education Institutions (HEIs) in Pakistan
}

\author{
Nighat Moin, \\ PhD-Scholar \\ University of Karachi \\ Faculty-Management Studies Department \\ Bahria University, Karachi \\ nighatmoin@gmail.com \\ Professor Dr. Syed Shabib-ul Hassan, \\ Vice Chancellor \\ Hamdard University \\ Karachi - Pakistan \\ huvc@hamdard.edu.pk
}

\begin{abstract}
Leveraging and fostering those resources for non-stop increase of the organization is similarly critical for somebody serving in a business to a person serving in teachers. Whether or not it is a worker of any organization or of any educational institute, a trained and content college can lead the institute to new heights whilst an opposite you'll be able to abate it badly. So, every resignation stored is each greenback earned and it's the faculty who provides standards and shapes the prospect of the kingdom through growing skills of the students because the facilitator and teacher for their self intensification as well as the increase of the financial system. A low retention price creates luxurious financial and academic effects for establishments and academic departments. Monetary outcomes consist of a misplaced go back on a preceding investment, the monetary expenditure of recruiting an alternative, and the instance of different universities and institutions diverted to the hiring manner. This article is reviewing and highlighting the prospects that effective Faculty employment is critical in attaining a first rate dwelling fashionable, social and economic development, and personal fulfillment. Further, these employees want to understand how additional praise and development are related to overall performance. This may help to take away any uncertainty as to what is expected of them and increase Faculty Retention.
\end{abstract}




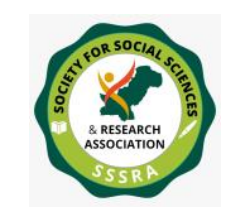

Pak. Journal of Int'L Affairs, Vol 4, Issue 1 (2021)

The Prospects Affecting Faculty Retention ..

\section{Key words}

Faculty Retention, Prospects, Policies, Higher Education Institutions (HEIs).

\section{Introduction}

Attracting, growing and keeping employees with certain channel of competent humans are indispensable for fulfillment of several organizations which we known as talent management. The distinction of instructional zone depends on the sort of humans capable of procure and hold of its faculties, it is the college that sets the tone of an academic group to transport ahead. The allocation of college has come to be a primary task for better instructional institutions, but a far larger challenge is that of an excessive earnings, considering that an amount of school individuals change organizations. The impulsive failure of these information pools affects on accessible educational tactics of business enterprise in a poor conduct. This has led to a situation in which institutions are vying with every different to draw and maintain for them the first-rate to be had college expertise.

Job security, endorsement and co-workers are important factors for university academics' job satisfaction. Relations with co-workers, supervision, company policy and support, promotion, and pay play vital role to retain employees and raise job satisfaction. Job satisfaction factors include power, management, policies and amenities, the work itself, interpersonal associations, pledge, remuneration and workload which are the main reasons to retain an employee (Basak, S. K., \& Govender, D. W. (2015).

Consequently, it's far of extreme significance that universities and HEIs must propose and practice guidelines as a way to participate sound in marketplace region to have a focus on and hold for them the exceptional staff ability. The success of the maximum aggressive groups in the course of the sector, consisting of better schooling institutions, lies of their pretty experienced faculty on which those universities/institutions pay out millions to hold. The three pillars of any advanced training group are excellence of school, infrastructure conveniences and getting to know atmosphere but one of the principal issues for better training is ensuring the constant superiority of its staff, to constantly get better and contend inside the destiny as the range and variety of higher education students is rising, developing an institutional surroundings that values the staffing and withholding of a great and varied staff is extra significant than ever. In line with the American administration affiliation, the largest expenditure on earnings is that of replacing a worker who leaves. Even as losing human resources is a very steeply-priced exercising, the substitution fees incurred comprise marketing and staffing fees, 


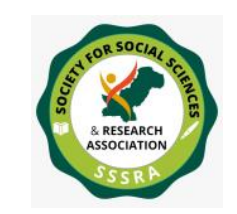

Pak. Journal of Int'L Affairs, Vol 4, Issue 1 (2021)

The Prospects Affecting Faculty Retention ...

orientation and working out of latest workforce, reduced efficiency until the fresh employee is up to the mark and failure of clientele who have been unswerving to the leaving worker. Correct college contributors are useful asset to any right instructional organization. The entire institution ought to try to forest all them from leaving the institute.

Employees depart because they have been pulled away by way of "extra pay" or "better possibility." Their primary career alternative is teaching in preference to corporate sector globally as they discovered their less strain, appropriate running environment, higher centers, strength \& position. Employees need to be well aware with the regulations \& processes in their institution. Realize the flexible and accommodating rules and programs that apply to university's brilliant overall performance to be identified thru earnings and different styles of repayment, and additionally, as suitable, via possibilities for management or for tasks of special interest to the institute member and the institution. Provision of external presents help for studies and different functions as a benefit to faculty members. Parenthood leaves for various durations of time, with or not including pay, in association with the beginning or taking up of a child, or residency of a kid for promote care. (Lavania, D., Sharma, H., \& Gupta, N. (2011).

Human capital is significant amongst all the sources an organization owns. To hold wellorganized and qualified team of workers in an organization is extremely essential in average on the whole act of an organization. Inspired human resources can assist and build an enterprise competitively greater worth delivered and cost-effective. In step with baron (1983, p. 123), inspiration is a buildup of various processes which manipulate and express our performance to gain some specific intention. Flynn (1998) argued that rewards and popularity packages maintain excessive state of mind between workforces, boosts up their drive and generate an association among act and drive of the workforce. The fundamental cause of reputation and incentive plan is to classify a mechanism to pay and communicate it to the employees to hyperlink their praise to their performance which in the long run leads to workers' process delight. Not extraordinarily, the research indicates that rising repayment tends to boom the pace of trainer retention, but this dating is not an easy one. Repayment has a various effect on retention depending on other elements including teachers' gender, degree of experience and cutting-edge job pride. There may be reasonable proof that working conditions may, in some instances, trump earnings as an aspect in trainer retention, and it miles the comparative revenue among districts that is the imperative concern. The research proof is questionable as to whether or not restrained profession-advancement possibilities in coaching make a contribution to slow destruction. With reference to faculty staffing, there's limited proof of a tremendous relationship among recruitment and numerous monetary incentives, such as 


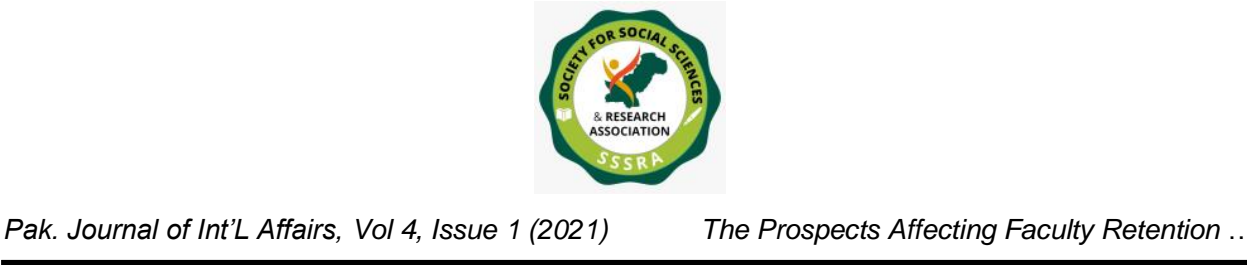

reimbursement. With reference to educator fine, the studies are uncertain as to whether monetary incentives have an effect (Allen, M. B. (2005).

The edifying implication of writing lies in its input to the structure of signs with the aid of which large communities generate their personal characteristics. Prose as part of a literary attention of a bigger organization turns into a place in which it's far determined what will be remembered. Mom tongue and literature is one of the primary topics inside the learning program of study. With a cautious range of literary mechanism within the program of study one of the mainly critical dreams of the learning manner can be performed, and this is the formation of learning and artistic competencies of universities/HEIs students and their contribution in building their personal literary identification, no longer only of their personal; however additionally as part of the multicultural of countries. The device of coaching courses for fashionable training across the world literary and a fashion oriented aspect which is collectively related. We will bring to a close that mores and learning are an indivisible whole this is in reality intended at the nurture of HEIs students from nursery age to the point in time of their formative years, and to the educational stage as properly. We build this assert, for the reason that we do at the present not give the impression of being the academic thing thru the prism of the implementation of a few primary moral regulations of behavior, however we look upon it as a vital technique of maturation, edifying growing wherein nurture has enduring obligations. They stand up from the contradictions in the social order which might be caused by the range of public (Dimova, V. (2011).

Employee pleasure affects organizational performance as much as consumer pleasure. Teachers are the workforce of training corporations, and trainer pleasure with the running situation can support lessons and research worth. Consequently, teacher necessities should be satisfied to perk up the operating situation and allow teachers to attain fantastic studies and coaching overall act. Consequently, employee pleasure surveys, especially on worker delight within the higher schooling quarter, nevertheless require look at and survey. Questionnaires, in addition to worker interviews can also be useful to study worker contentment. Disappointed workers are at risk of immoderate turnover and absenteeism. Knowledge activity contentment thus can be connected to overall act, managerial productiveness and different matters, along with workforce proceeds (dickter et al., 1996; lee et al., 1999; melamed et al., 1995; sekoran and jauch, 1978). Perkins (1973) proposed that HEIs teachers satisfy three principal functions, specifically coaching, gaining knowledge of and administration and management (Chen, S. H., Yang, C. C., Shiau, J. Y., \& Wang, H. H. (2006). 


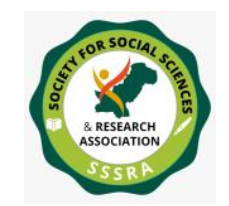

The Prospects Affecting Faculty Retention ..

Indeed, social psychologists have located societal company to be extraordinarily correlated. Sociologists and anthropologists do not forget the business enterprise of society to be a reflection of its way of life-a critical element of that is cultural ideals. Cultural beliefs are the thoughts and thoughts are common to numerous people that govern interaction among these human beings and among them, their gods, and other agencies and vary from understanding in that they're now not empirically determined or analytically proved. Cultural beliefs also impact societal corporation in view that strategic interactions arise inside a specific social and historical context. The analysis demonstrate that how the interactions between establishments, exogenous adjustments, and the process of organizational innovation govern the ancient development of societal company and the associated economic, political, criminal, and social constructs. Every of those factors complement the others to generate a self-sustained system, and each of the two structures analyzed on this paper has unique performance implications (Greif, A. (1994). Their job delight become considerably (unconstructively) linked to particular dilemma checks (e. G., dependency of universities on the state and political parties). As a final point, the greater glad HEIs members assessed as much fewer extreme the senior schooling troubles in comparison to their fewer glad friends. Though, pragmatic proof concerning occupation contentment of HEIs faculty is in short supply inside the global prose (oshagbemi, 2003; tack \& patitu, 1992).

In keeping with Pearson and seiler (1983), this vicinity has no longer obtained a whole lot attention because an excessive degree of task delight has commonly been alleged to subsist in an institution of higher education putting. In line with bellamy (1999, noted in bellamy, morley, \& watty, 2003), faculty members are in the main influenced via internal reasons (e. G., autonomy, displaying initiative, highbrow challenges) instead of external reasons (e. G., economic or social rewards). The limitation of the kingdom to conjure up the crucial issues of institutions of higher education with the aid of the universities and the dearth of formal evaluation processes and mechanisms in higher education the weak point of better training is to bring into line by means of the demands and formal evaluation approaches and mechanisms in higher education. The approaches observed for the appointment of management workplaces in the university the manner in which evaluation and promoting of academics take area the "introversion" of higher education institutes the "entrepreneurism" of better training (Platsidou, M., \& Diamantopoulou, G. (2009). As institutions of better education have ended up an increasing number of complicated corporations, the problem of institutional governance has turn out to be a factor of predominant competition on numerous campuses (gerber, 2001; simplicio, 2006). Collective authority refers to the collective responsibility among management and college for most important selections approximately the common way of advancing the general instructional coverage resolute by using the college's 


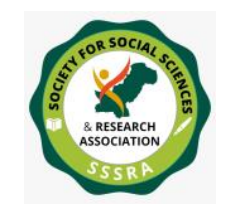

Pak. Journal of Int'L Affairs, Vol 4, Issue 1 (2021)

The Prospects Affecting Faculty Retention ...

constitution (flynn, 2005, p. 1). Common authority is the set of practices in which university academy and team of workers contribute in good sized selections with reference to the action in their establishments (American federation of instructors, 2006, p. Four). This convention of participation in institutional authority, though, has no longer usually been the standard inside American higher education. The expansion of the research university in the late 19th century, the multiplied professionalism of college within the early 20th century, fast enrollment increase, the converting composition of the student body, and the unstable political weather within the fifties and 1960s all helped to growth school influence in numerous regions of institutional governance (Birnbaum, 2004; Dill \& helm, 1999; Morphew, 1999) (Jones, W. A. (2011). Mcguinness (1994) attracts a beneficial difference between systems of university authority and styles of statewide synchronization; the previous refers back to the manner where in a kingdom gives for the daily administration of its public better schooling establishments, even as the latter refers to the manner wherein a country enables the coordination of its normal higher schooling system. American better schooling and the regular enlargement of nation governmental manipulate over the better instructional business enterprise (McLendon, M. K. (2003). McGuiness (1994) attracts a useful difference among systems of university authority and varieties of statewide coordination; the former refers to the manner wherein a nation gives for the everyday management of its public higher education establishments, while the second refers back to the manner in which a rustic allows the coordination of its regular higher schooling system.

\section{Literature Review}

According to Oshagbemi (2003), job position intensity and professional level are the factors that are typically measured as causal to job contentment. In expansion to look into proof, at that point, policymakers or teachers need to have great data or else go out on a limb a that the reception of a strategy or agenda demonstrated fruitful in one situation additionally will be fruitful in another. In spite of these constraints, inquire about contributes significant data for strategy choices. The influence of research proof and particularly solitary research learning is by no means an adequate direct for approach choices, yet choices that contradict a considerable assortment of high-quality research are probably going to be ineffectual and conceivably even grievous. Keeping in mind that not in any case an entire group of research on a specific inquiry will give complete answers, the decision of numerous exploration thinks about ought to be viewed as the most solid guide accessible. (Allen, M. B. (2005). One of the most unmistakable culturologists Leslie White, considers culture to be an outside power which decides both the individual and the general public furthermore; subsequently the culture and society are commonly associated. It tends to be effectively said that the social regulations of people certainly 


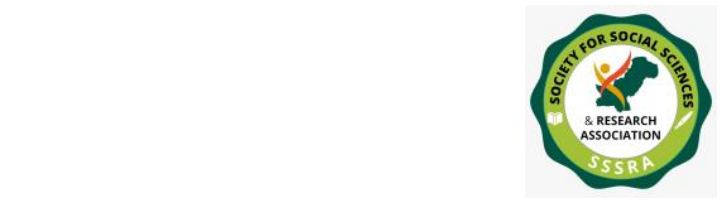

The Prospects Affecting Faculty Retention ...

incorporates instruction, that is, the more propelled arrangement of instruction, the improved the arrangement of social qualities that are consolidated in the psychological lattice of our understudies, youngsters, and who and what is to come. Culture is the way in to the understanding of a bit of effort since it emerges from the premise of a specific social custom and is socially acknowledged in its system. The semantics of a creative content can be seen distinctly in a social setting, implying that the work of art must be considered at an expansive social level. Culture gives a system that enables anybody to peruse and comprehend. Be that as it may, to accomplish stylish objectives of showing writing, an alternate methodology is fundamental, and that is open instructing of writing which will be connected to different subjects, for example, topography, human science, brain research, and obviously, language and correspondence, including the data and correspondence innovation as a major aspect of the most recent social accomplishments within recent memory.

Promotional opportunities have a helpful blow on the employees' job contentment (Ellickson and Longsdon (2001). A significant component in the arrangement of training is the understudies' recreation time, as planning for their further advancement and way of life in some future point of view - as a grown-up. Opportunity of assortment of movements that the understudy will take up in his/her additional time, offers the possibility to successfully take an attention in societal existence and the opportunity to establish their exceptionality, imagination and difficulty (Dimova, V. (2011).

Teachers are the representatives of training associations, and educator fulfillment with the working condition can advance instructing and research quality. Along these lines, educator necessities must be satisfied to improve the workplace and empower instructors to accomplish remarkable research and educating execution. In advanced education, most examinations center around understudies as "clients", and assess their degree of fulfillment/disappointment with their projects of study (Comm and Mathaisel, 2000), while by and large ignoring instructor work fulfillment. While a few representative fulfillments considers have been performed, not many arrangement with college instructors or scholastics all in all (Ward and Sloane, 1998). Since representative fulfillment has been seen as significant as client (understudy) fulfillment (Oshagbemi, 1997a), investigate on advanced education quality has now additionally started to considering scholarly fulfillment (Comm and Mathaisel, 2003). Occupation fulfillment has been secured to essentially impact position execution, truancy, turnover, and mental trouble (Andrisani, 1978; Davis, 1992; Spector, 1997). Disappointed specialists are inclined to exorbitant turnover and truancy. Understanding occupation fulfillment along these lines might be connected to execution, hierarchical profitability and different issues, including work turnover (Dickter et al., 1996; Lee et al., 1999; Melamed et al., 1995; 


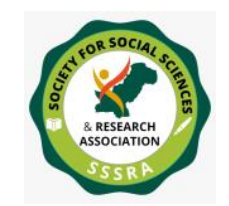

Pak. Journal of Int'L Affairs, Vol 4, Issue 1 (2021)

The Prospects Affecting Faculty Retention ...

Sekoran and Jauch, 1978). Representative fulfillment is as significant as consumer loyalty in impacting authoritative execution. Lee (1988) demonstrated that activity fulfillment is among the best indicators of turnover. The goals of advanced education are to give inside and out information, look for scholastic improvement, teach understudies, and organize national advancement requests (Johnes furthermore, Taylor, 1990). Perkins (1973) suggested that college instructors satisfy three significant capacities, specifically instructing, exploring and organization and the board. Thusly, college instructor fulfillment is identified with the elements of higher Representative fulfillment model training. Dalton and Pica (1998) found that the nature of staff and guidance are significant components for fulfilling business students and graduates, and that business situation and administrations were imperative to understudies. Essentially, in the higher instruction area, Oshagbemi (1997a) researched work fulfillment among college educators. Hagedorn (1994) analyzed the fulfillment of scholarly staff utilizing different factors, including compensation, saw support from associates, fulfillment with organization, delight in understudy collaboration and saw feelings of anxiety. Educators are generally worried about pay rates and work security, and wish to have stable employments and pay rates. Instructors are worried about advancement chances to a more significant level, so reasonable advancement frameworks are significant. Furthermore, great retirement frameworks and long haul work security upgrade instructor certainty at school; inquire about is principal to crafted by educators, and hence plenteous research assets are additionally pivotal. The logical outcomes exhibit that educators' center around pay rates and reasonable advancement, and care minimal about welfare and workplaces. For instruction associations, representatives setting an unnecessary Worker fulfillment model esteem on their pay rates show that representative may haphazardly work bounce to pursue higher compensations, affecting school assurance. Chen, S. H., Yang, C. C., Shiau, J. Y., \& Wang, H. H. (2006).Comm, C. L., \& Mathaisel, D. F. (2003). Worker fulfillment is assessed in a one of a kind assistance condition: advanced education. This contextual investigation explicitly centers on how data with respect to workforce remaining task at hand, pay, and advantages can be utilized to improve scholarly quality. One significant discovering is that a large portion of the workforce overviewed doesn't accept they are genuinely redressed, nor do they believe they are getting institutional acknowledgment for their commitments. Subsequently, half of the workforce in this review looked for proficient pay outside the school. Subsequently, the issue of their promise to the college, and scholastic quality, emerges (Comm, C. L., \& Mathaisel, D. F. (2003). Analysts have inferred that while work fulfillment will in general increment over the range of a scholastic vocation, the calling comprises of a progression of unsurprising valleys subject to profession arrange (Baldwin, 1979; Baldwin and Blackburn, 1984). The early vocation phase of staff has been depicted as a period of serious time pressure (Eble and McKeachie, 1985) yet additionally as intemperate by routine or show (Baldwin, 


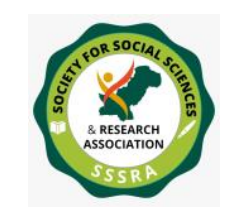

Pak. Journal of Int'L Affairs, Vol 4, Issue 1 (2021)

The Prospects Affecting Faculty Retention ...

1990). Hagedorn, L. S. (1994). The examination saw that while scholastics showed up as extremely happy with the center errands of instructing, and, to a lesser degree, investigate, they were obviously disappointed with different parts of their activity including their pay rates and advancement possibilities (Oshagbemi, T. (1996). Enquires whether HEIs educators can be definitively assembled based on the fulfillment levels which they appreciate on different parts of their employments (Oshagbemi, T. (1997). Age and length of administration are not essentially related legitimately with the general employment fulfillment, a few of the intelligent connections of the factors, for example, rank and sex or length of administration in advanced education and age, are measurably huge; while scholastic position is decidedly and emphatically corresponded with the general occupation fulfillment, (Oshagbemi, T. (2003). Representative fulfillment and maintenance have consistently been significant issues for doctors.

The marvel of Brain channel (BD) is the "relocation of talented human assets looking for improved anticipation for day by day comforts and individual contentment, senior compensations, right of entry to trend setting innovation and increasingly stable political circumstances in enhanced places worldwide for exchange, training, and so forth" Afridi, F. K., \& Afridi, W. (2016). Nonetheless, observational proof in regards to work fulfillment of advanced education instructors is rare in the universal writing (Oshagbemi, 2003; Tack and Patitu, 1992). As indicated by Pearson and Seiler (1983), this territory has not gotten a lot of consideration in light of the fact that a significant level of occupation fulfillment has for the most part been dared to exist in a college setting. Regardless of whether this assumption is valid or not will be investigated in the current paper. The qualities of the scholastic calling are not much of the time met in different callings, for example, self-governance, opportunity and adaptability just as the instructing/inquire about clash, the residency framework which gives work (in) security, and so on. (Kelly, 1989). As indicated by Bellamy (1999, referred to in Bellamy, Morley, and Watty, 2003), scholastics are for the most part persuaded by inside thought processes (e.g., self-rule, demonstrating activity, scholarly difficulties) as opposed to outside intentions (e.g., monetary or social prizes). Because of the above mentioned, the scholastics' activity fulfillment seems, by all accounts, to be identified with interior as opposed to outer elements of their expert exercises.

\section{Analysis}

Professional progress and earnings are the most significant job contentment factors. However, the association behavior of administrative body has a consequence on faculty job satisfaction. Research finds that positive relationships with fellow workers increase with the job satisfaction and relationships with co-workers are improved when employees 


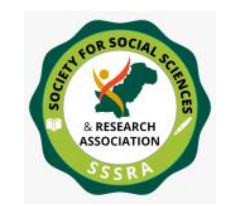

Pak. Journal of Int'L Affairs, Vol 4, Issue 1 (2021)

The Prospects Affecting Faculty Retention ..

experience job satisfaction. The operational surroundings increase employees' job satisfaction very certainly and rewards increase and decrease the satisfaction of employees (Ghaffar et al. (2013). The substance of the work itself (instructing/inquire about), independence, adaptability, activity conduct, nature of relations with associates and understudies, the sentiment of "having a place" to a high social and taught network and, at long last, the meritocracy and equity in the arrangement of advancements (when they are available) have been brought up as the principle variables of employment fulfillment of educators in advanced education. In any case, the observational information concerning the effect of statistic, institutional and individual factors on their activity fulfillment are befuddling. The comparative discoveries shift with respect to which of these variables (e.g., sex, mores, work accomplishment, nature of work, pay, uncompetitive connections, position and residency) influence the degree of employment fulfillment of scholastics. The way that the quantity of the comparative examinations is constrained makes it harder to make strong determinations (Oshagbemi, 2003). We will quickly portray the most significant of these discoveries for our investigation. Rank and residency are extra control factors for personnel work fulfillment (Sabharwal and Corley, 2009). Proof shows that rank is an exceptionally huge indicator of occupation fulfillment among scholastics, with full teachers communicating more prominent employment fulfillment than junior employees (Oshagbemi, 1997).

Likewise, tenured employees have higher occupation fulfillment levels than untenured employees (Bender and Heywood, 2006). In any case, it must be noticed that, in an examination performed in Northern Cyprus, the degree of employment fulfillment of the scholastics didn't increment with scholarly position (Eyupoglu and Saner, 2009). The scholarly positions of the employees utilized in the Greek colleges run from Lecturers (this post requires a $\mathrm{PhD}$ yet isn't tenured), Assistant Professors (it begins as a nonresidency position and becomes secure three years after the fact, if an individual effectively passes the assessment), Associate Professors and Full Professors (these are residency posts), (Jones, W. A. (2011).

As establishments of advanced education have become progressively perplexing associations, the issue of institutional administration has become a point of significant conflict on numerous grounds (Gerber, 2001; Simplicio, 2006). Researchers occupied with inquire about on staff feelings about shared administration have essentially centered around two regions; workforce convictions about the significance of imparted administration and personnel insights about their degree of inclusion in administration. Minor (2005), notwithstanding, discovered proof that workforce in one portion of the advanced education network were not as liable to see shared administration as a significant piece of institutional character. In his investigation of staff at Historically 


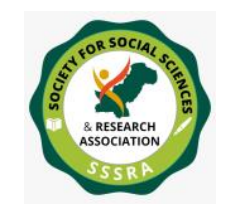

Pak. Journal of Int'L Affairs, Vol 4, Issue 1 (2021)

The Prospects Affecting Faculty Retention ...

Black Colleges and Universities (HBCUs), over $75 \%$ of personnel didn't consider workforce to be as a significant piece of their organization's worth and character. Personnel cooperation in administration gives off an impression of being acknowledged as an alluring and significant piece of advanced education. Jones, W. A. (2011). Then again, better wages what's more, work circumstances; improved statistics, enlistment, and less costly shipping are influence gifted transients to look for occupations in created economies. Globalization is linking mutually job markets building effort streams that range international metropolitan communities that are recognized in chains of significance of work claim. No worldwide framework for recording talented displacement exists. As result the expression "gifted" is frequently deciphered in the writing as far as instructive achievement. One financial model recommends that, at a sufficiently high volume of gifted migration, the portion of gifted laborers in the basis nation really grows. As enlistments increment prodded by the possibility of resettlement, normal human capital increments and, along these lines, by and large source nation development can be animated. High paces of return relocation after brief remains abroad might be the best of all in an "ideal cerebrum channel" world. Local laborers may seek after advanced education with expectations of traveling to another country, and on the off chance that they return they can expand source nation normal efficiency, particularly if the laborer returns after picking up understanding and aptitudes in a further developed economy. Numerous eyewitnesses accept that paces of return are sufficiently high-all things considered at any rate half of talented specialists seem to come back from a large amount spells overseas - to necessitate getting rid of the expression mind channel all together, leaning toward terms like "cerebrum dissemination" or "expert humanity." Multinationals that transition to creating nations have ordinarily brought along their own the board and talented laborers.

The accessible proof recommends that transnational organizations are moderately delayed to utilize nearby or outsider nationals in higher-ranking positions, substantially a smaller amount to move about them to elevated level administrative posts in other worldwide locations. sooner or later in the change to more prominent exchange universal administrations creating nations may hold and return gifted transients: the Republic of Korea, Taiwan (China), Hong Kong (China), and Singapore are such models. Increments in portability seem, by all accounts, to be personally tied both to the tertiarisation of work powers and the significance of administrations in world exchange, particularly in creating economies. The increasing speed of globalization makes new examples of universal speculation and ability trades. While these patterns may have at first profited created nations, prepared models exist of creating nations taking part in and profiting by the global exchange services. 


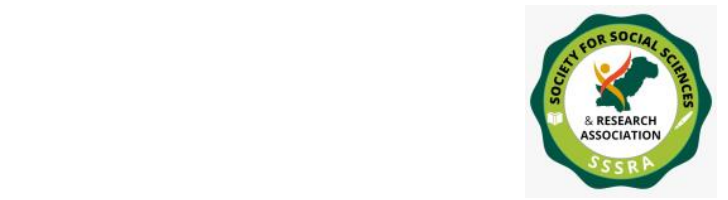

The Prospects Affecting Faculty Retention ...

Arrangement responses to far above the ground experienced mobility in mutually created and creating nations there is a scope of arrangements that are sought after in reaction to the displacement of exceptionally gifted specialists. In any event six broad approach types can be recognized, every one of which has subtypes and shifted instances of approaches that are really executed. Terrific strategies of maintenance are probably going to be the best since quite a while ago run reaction to high volumes of high talented out relocation.

Undoubtedly, in the momentary advancement can really prompt increments in displacement, however above the extended haul this is the most ideal approach to lessen remuneration differentials and circumstances that show the way to significant levels of gifted resettlement. The largest part dynamic approaches contain and keep on being scholarly adventures dependent on local and global participation where getting nations assume a functioning job. Also, many creating nations have independently, or with regards to provincial accords, directed ICT improvement as a method for jumping on the data age temporary fad. Such undertakings guarantee to be a productive method for animating monetary development and decreasing lasting out movement of profoundly instructed locals. While a free outline can be spread out on government reactions, there has been little in the method for orderly exchange of how most ideal to address the antagonistic outcomes of high gifted portability from creating nations. This report offers the accompanying arrangement bearings for policymakers in created accepting nations. Migration arrangements in source and sending nation should be adaptable, effective, straightforward, and are best tended to in provincial understandings and the GATS. Diaspora alternatives pack together countless techniques that are fundamentally under the aegis of sending nations, yet accepting nations can contribute.

Education, preparing, and focused on financial advancement may really increment gifted relocation in the short-to-medium term, yet it is the best methods for tending to creating nation ability deficiencies. Movement approaches to encourage and ensure in a worldwide economy. Movement approaches that encourage the needs of a cutting edge financial system be able to be to the benefit mutually of accepting nations just as creating countries. The work out in cautious direction comes in formulating approaches that support not by building the whole thing "uncomplicated to do," yet by dealing with the process in a method that secures residential job markets and the economic premiums of creating nations. Encouraging methods adjustable, effective, and clear-cut arrangements. Encouraging portability doesn't signify an unlock entrance strategy; it implies movement approaches that are compliant, effective, what's more, straightforward. Adaptable movement approach licenses expanded supplies of remote laborers at the point when demand is hot, yet limits right of entry to remote laborers when demand is behind. It 


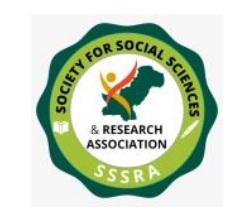

Pak. Journal of Int'L Affairs, Vol 4, Issue 1 (2021)

The Prospects Affecting Faculty Retention ...

ensures local job markets. Valuable faction arrangement conveys a remote expert for a work in a procedure that is rapid and the desk work ought to be insignificant. It meets bosses' work request. Straightforward arrangement conveys plainly characterized guarantees: transients and bosses Encouraging return repositioning. Merchandise exchanges might be dynamic or data based.

Unavoidably, dialogs of teaching at the University level adopt up philosophies of education. Differing strategies spin around innovation, effectiveness, and learning (Buhl, L. C., \& Lane, S. H. (1973). The matter of measures is consistently troublesome. Granted that there are no absolutes, it is all considered conceivable to demand that in each of the college discipline, certain degrees of dominance and under-standing must be kept up (Buhl, L. C., \& Lane, S. H. (1973). Inspiration is such a reason that applies a major impetus on our actions and effort. As per Baron (1983, p. 123), inspiration is an aggregation of a variety of actions which contact and express our carry out to achieve a number of particular aim. As per Broad (2007), considerable motivating forces are feasible in mounting implementation for task not done formerly, to give power to "belief further astute" and to assist both eminence and quantity to achieve objectives.

A functioning project would be the International Organization for Migration (IOM) plan of go back that supports the ostracize family's arrival and sets up them in their home nation. Financing for such a plan legitimately originates from administrative or global hierarchical sources. although to some degree expensive, covering differently quest for new employment, travel, what's more, resolution, the expense of such projects in the standard time is probably going to be little comparative with the points of interest it makes for the cause nation, just as the expansion in worldwide efficiency above the more drawn out run. Longer-term projects of go back as on account of Germany and Turkey (which for the most part applied to semi-and low-gifted. Worldwide movement strategies: from respective understandings to coordination. There is wide understanding that in a perfect world together vagrant getting and basis nations would work from a similar content on high expertise portability. Practically speaking, a fit worldwide system, like the regime(s) that have been advancing for quite a few years to control exchange associations, will take years if not decades to build. Preferences of respective and multilateral understandings. Numerous members in this discussion advocate respective and local concessions to specialist portability. Such understandings have long administered development from impermanent horticultural specialists to restorative work force. It is conceivable to engage the estimation of groups of between administrative understandings among created and a modest number of creating nations. Respective and multilateral understandings have the advantage of allowing experts in created nations to liaise legitimately with those administrations in creating nations wishing to briefly send 


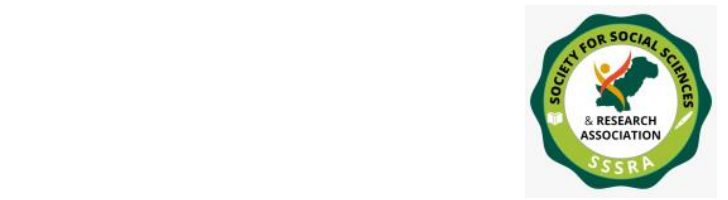

The Prospects Affecting Faculty Retention ...

out exceptionally talented laborers whom they also observe as excess to their infrastructural requirements, or people whom sending governments have distinguished as applicants whose abilities could be improved through functioning in a specific instructive field overseas. The move toward of utilizing between administrative accords to create relocation linkages likewise has the obvious advantage that it maintains a strategic distance from conceivably harming impacts of head chasing by universal enlistment organizations looking for outside specialists from the least demanding sources in the creating nations. Simultaneously, reciprocal understandings can stipulate that remote laborer preparing in aptitudes fitting to the necessities of the creating nation be a piece of an incorporated program. Improvement offices could aim interest in the basis nation that animates the part behind the gifted specialists, as a piece of a bundle planned not exclusively to get better the possibilities of the basis nation, yet as a methods for guaranteeing that circumstances are progressively appealing for return movement. Such understandings are generally suitable for those occupations that are in interminable shortage in created nations and in which firm source nations encompass a specific favorable position. Restorative claims to fame have verifiably fallen into this class and fulfilling need to support the maturing social orders of the created world will stay a test. $\mathrm{Be}$ that as it may, two-sided and local understandings are less fitting for meeting present moment or cyclic deficiencies (B. Lindsay Lowell, Allan M. Findlay, . (2001).

\section{Conclusion}

Motivating forces, rewards and acknowledgments are the key factors that effect on worker inspiration. It is such a vibrant in the current circumstance that unambiguously makes and includes an optimistic result on effort. As responsibility of all legislative body depends on rewards and recognition. It is contended that success and endurance of the links is determined all the way through the HR how they are dealt by means of. The greater part of links have pulled out up the tremendous advancement by entirely going along by means of their dealing technique in the course of an extremely a great deal attuned incentive and recognition plans for member of staff. In the history, educator's own aptitudes and capacities, successful instructing relies upon the condition in which an individual is instructing. An educator might be exceptionally powerful instructing in one sort of condition however not in another. There are expenses related with soaring paces of instructor return together monetarily and as far as making a profitable learning condition.

Preferably, the instructing calling could profit by employing promising starting educators who might stay in the work for more than just five or six years, especially since certain investigations show that educator practicability increases essentially through the span of 


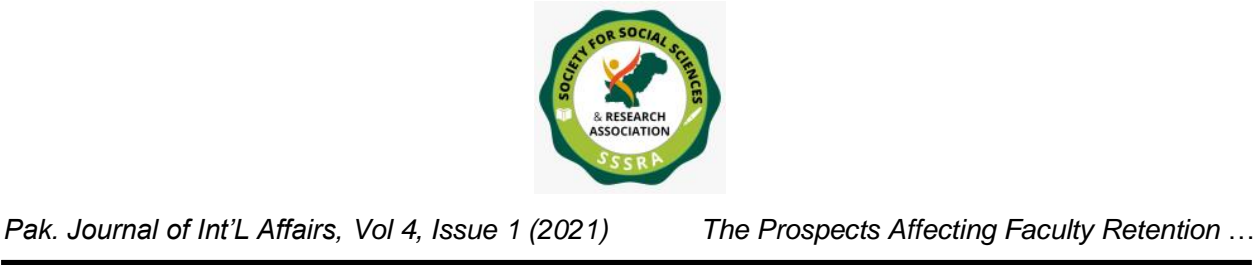

that time. It might be unreasonable, be that as it may, given the ease of individuals' vocations nowadays to anticipate that most educators should stay in a given viewing situation for 10 years or even to stay in the occupation itself for any longer than that instance. Toward the end, obviously, instructor staffing and maintenance are nearby issues that require locally proper arrangements. The ideas of teacher deficiencies, of the cosmetics and appropriation of the instructor personnel, and of the techniques that will work in the work advertise vary from locale to area and state to state. By and by, the wide depiction that explore examination tries to cover is probable to mirror the area circumstance in numerous states and locale. Ideally, the significant data furthermore, bits of knowledge contained here will support teachers and policymakers create their own specific ways to deal with the difficulties they face. At long last, it is significant not to dismiss the way that the concern of educator employment and maintenance is identified with the matter of teachers' excellence. It isn't just about guaranteeing a satisfactory number of teachers for the U.S. academies are accessible; however regarding having the instructors in the line of work who are as practiced as could reasonably be expected. Educator pact programs need to select the most encouraging teachers they can and fabricate the limit of their volunteers through strong educator instruction. In like manner, when teachers are in the study hall, states and locale must keep on improving their aptitudes and information through top notch proficient improvement. Achievement for the most part relies upon the union of various elements that may not be effectively imitated or that may not be recognized in the examination as imperative to the results watched. 
The Prospects Affecting Faculty Retention ...

\section{References}

Afridi, F. K., \& Afridi, W. (2016). An Analysis of Factors Preventing and Reversing Brain Drain Phenomenon in Khyber Pakhtunkhuwa: Evidence from Education Sector. Journal of Managerial Sciences Volume X Number, 2, 232.

Allen, M. B. (2005). Eight Questions on Teacher Recruitment and Retention: What Does the Research Say?. Education Commission of the States (NJ3).

Basak, S. K., \& Govender, D. W. (2015). Theoretical Framework Of The Factors Affecting University Academics Job Satisfaction. International Business \& Economics Research Journal (IBER), 14(2), 317-326).

Berry, L. L., Zeithaml, V. A., \& Parasuraman, A. (1990). Five imperatives for improving service quality. MIT Sloan Management Review, 31(4), 29.

Buhl, L. C., \& Lane, S. H. (1973). Innovative Teaching: Issues, Strategies, and Evaluation.

Chen, S. H., Yang, C. C., Shiau, J. Y., \& Wang, H. H. (2006). The development of an employee satisfaction model for higher education. The TQM Magazine, 18(5), 484-500.

Comm, C. L., \& Mathaisel, D. F. (2000). Assesssing employee satisfaction in service firms: An example in higher education. The journal of business and economic studies, 6(1), 43.

Comm, C. L., \& Mathaisel, D. F. (2003). A case study of the implications of faculty workload and compensation for improving academic quality. International Journal of Educational Management, 17(5), 200-210.

Danish, R. Q., \& Usman, A. (2010). Impact of reward and recognition on job satisfaction and motivation: An empirical study from Pakistan. International journal of business and management, 5(2), 159.

Dimova, V. (2011). Education and Culture. Procedia-Social and Behavioral Sciences, 15, 2357-2359. 


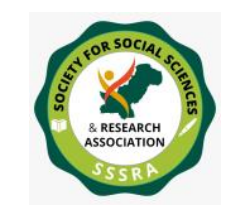

Pak. Journal of Int'L Affairs, Vol 4, Issue 1 (2021)

The Prospects Affecting Faculty Retention ...

Ellickson, M. C., \& Logsdon, K. (2001). Determinants of job satisfaction of municipal government employees. State and Local Government Review, 33(3), 173-184.

Findlay, A. M., \& Lowell, L. B. (2001). Migration of Highly Skilled Persons from Developing Countries. Impact and Policy Responses. Report. International Labour Office (ILO), Genf.

Goldhader, D. D., Brewer, D. J., \& Anderson, D. J. (1999). A three-way error components analysis of educational productivity. Education Economics, 7(3), 199-208.

Greif, A. (1994). Cultural beliefs and the organization of society: A historical and theoretical reflection on collectivist and individualist societies. Journal of political economy, 102(5), 912-950.

Ghaffar, A., Ameer, B., Arshad, N., \& Urooj, F. (2013). Factors affecting job satisfaction level of academic staff in Pakistan. Journal of Education and practice, 4(6), 181203.

Hagedorn, L. S. (1994). Retirement proximity's role in the prediction of satisfaction in academe. Research in higher education, 35(6), 711-728.

Johnes, J., \& Taylor, J. (1990). Performance Indicators in Higher Education: UK universities (Buckingham, Society for Research into Higher Education \& Open University Press).

Jones, W. A. (2011). Faculty involvement in institutional governance: A literature review. Journal of the Professoriate, 6(1), 118-135.

Lavania, D., Sharma, H., \& Gupta, N. (2011). Faculty recruitment and retention: A key for managing talent in higher education.

Lowell, B. L., \& Findlay, A. (2001). Migration of highly skilled persons from developing countries: impact and policy responses. International migration papers, 44, 25.

McLendon, M. K. (2003). State governance reform of higher education: Patterns, trends, and theories of the public policy process. In Higher education: Handbook of theory and research (pp. 57-143). Springer, Dordrecht.

Oshagbemi, T. (1996), “Job satisfaction of UK academics”, Educational Management \&

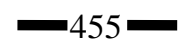


Administration, Vol. 24 No. 4, pp. 389-400.

Oshagbemi, T. (1997a), "Job satisfaction profiles of university professors", Journal of Managerial Psychology, Vol. 12 No. 1, pp. 27-39.

Oshagbemi, T. (2003). Personal correlates of job satisfaction: empirical evidence from UK universities. International journal of social economics, 30(12), 1210-1232.

Platsidou, M., \& Diamantopoulou, G. (2009). Job safisfacfion of Greek university professor: Is it affected by demographic factors, academic rank and problems of higher educafion. Proceedings, ESREA-ReNAdET. Thessaloniki: Grafima Publications (pp, 535, 545.

Syptak, J. M., Marsland, D. W., \& Ulmer, D. (1999). Job satisfaction: Putting theory into practice. Family practice management, 6(9), 26.

Williams, M. L. (1995). Antecedents of employee benefit level satisfaction: A test of a model. Journal of Management, 21(6), 1097-1128. 